University of Wollongong

Research Online

Faculty of Engineering and Information

Faculty of Engineering and Information

Sciences - Papers: Part A

Sciences

$1-1-2010$

Exploring the social implications of location based social networking: an inquiry into the perceived positive and negative impacts of using LBSN between friends

Sarah Jean Fusco

University of Wollongong, sjf462@uow.edu.au

Katina Michael

University of Wollongong, katina@uow.edu.au

M G. Michael

University of Wollongong, mgm@uow.edu.au

Roba Abbas

University of Wollongong, roba@uow.edu.au

Follow this and additional works at: https://ro.uow.edu.au/eispapers

Research Online is the open access institutional repository for the University of Wollongong. For further information contact the UOW Library: research-pubs@uow.edu.au 


\title{
Exploring the social implications of location based social networking: an inquiry into the perceived positive and negative impacts of using LBSN between friends
}

\author{
Abstract \\ Location based social networking (LBSN) applications are part of a new suite of emerging social \\ networking tools that run on the Web 2.0 platform. LBSN is the convergence between location based \\ services (LBS) and online social networking (OSN). LBSN applications offer users the ability to look up the \\ location of another "friend" remotely using a smart phone, desktop or other device, anytime and \\ anywhere. Users invite their friends to participate in LBSN and there is a process of consent that follows. \\ Friends have the ability to alter their privacy settings to allow their location to be monitored by another at \\ differing levels of accuracy (e.g. suburb, pinpoint at the street address level, or manual location entry). \\ This paper explores the impact of LBSN upon society, especially upon trust between friends. The study \\ used focus groups to collect data, and a qualitative approach towards analysis. The paper concludes that \\ while there are a great many positive uses of LBSN, there are some significant problems with current \\ applications, and that better design is required to ensure that these technologies are not exploited against \\ a user to commit harm.

\section{Keywords} \\ between, Ibsn, impacts, negative, positive, perceived, into, inquiry, networking, location, friends, \\ implications, exploring, social

\section{Publication Details} \\ Fusco, S. Jean., Michael, K., Michael, M. G. \& Abbas, R. (2010). Exploring the social implications of \\ location based social networking: an inquiry into the perceived positive and negative impacts of using \\ LBSN between friends. Ninth International Conference on Mobile Business/2010 Ninth Global Mobility \\ Roundtable (pp. 230-237). Piscataway, New Jersey, USA: IEEE.
}




\title{
Exploring the Social Implications of Location Based Social Networking
}

\author{
An inquiry into the perceived positive and negative impacts of using LBSN between friends
}

\author{
Sarah Jean Fusco, Katina Michael, M.G. Michael, Roba Abbas \\ School of Information Systems and Technology, Faculty of Informatics \\ University of Wollongong \\ Wollongong, NSW, Australia \\ $\{$ sjf462, katina, mgm, ra75\} @uow.edu.au
}

\begin{abstract}
Location based social networking (LBSN) applications are part of a new suite of emerging social networking tools that run on the Web 2.0 platform. LBSN is the convergence between location based services (LBS) and online social networking (OSN). LBSN applications offer users the ability to look up the location of another "friend" remotely using a smart phone, desktop or other device, anytime and anywhere. Users invite their friends to participate in LBSN and there is a process of consent that follows. Friends have the ability to alter their privacy settings to allow their location to be monitored by another at differing levels of accuracy (e.g. suburb, pinpoint at the street address level, or manual location entry). This paper explores the impact of LBSN upon society, especially upon trust between friends. The study used focus groups to collect data, and a qualitative approach towards analysis. The paper concludes that while there are a great many positive uses of LBSN, there are some significant problems with current applications, and that better design is required to ensure that these technologies are not exploited against a user to commit harm.
\end{abstract}

Keywords-location based services, online social networking, location based social networking, trust, friendship, implications

\section{INTRODUCTION}

Location Based Social Networking (LBSN) applications such as Google Latitude, Loopt and BrightKite enhance our ability to perform social surveillance. These applications enable users to view and share real time location information with their "friends". With the emergence of this technology it is crucial to consider that "technology alone, even good technology alone is not sufficient to create social or economic value" [1]. Further to not contributing "sufficient" economic or social value, Kling and other scholars have identified that technologies can have negative impacts on society [2].

As location based social networking technologies are used between "friends" they have the potential to impact friendships, which are integral not only to the operation of society but also to the individual's well being [3]. By enabling real-time location tracking of "friends" LBSN puts LBS technologies in the hands of "friends" while also enhancing the experience of online social networking (OSN). In essence it meshes together the positives and negatives of OSN and LBS creating a unique domain of enquiry, forcing researchers to ask new questions. The purpose of this paper is to explore the implication of location based social networking upon "friendships", with a particular focus on the impact upon trust.

\section{SOCIAL INFORMATICS}

Social informatics aims to "explore, explain and theorize about the social technical contexts of information communication technologies" [4] with a view to developing "reliable knowledge about information technology and social change based on systematic empirical research, in order to inform both public policy issues and professional practice" [5]. In this way social informatics looks at the broader picture of the implementation of information communication technologies (ICT), to understand their operation, use and implications. By undertaking research on location based services from a social informatics perspective, the credible threats of the technology, and the circumstances they arise within and their severity can be identified. One of the key concepts underlying the approach of social informatics is that "information technology are not designed or used in social or technological isolation. From this standpoint, the social context of IT influences their development, uses and consequences" [6]. Social informatics takes a nuanced approach to investigating technologies and explores the bidirectional shaping between context and ICT design, implementation and use [4] as is depicted in Figure 1.

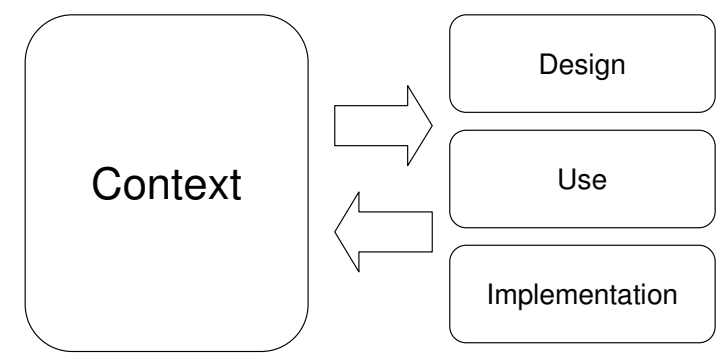

Figure 1. Bidirectional Shaping between Context and ICT Design

This approach, which combines the social aspects and the technical aspects of technology, has been found to be useful for understanding the social shaping and consequences of information communication technologies [7]. Examples of social informatics research include the vitality of electronic journals [8], the adoption and use of Lotus Notes within 
organizations [9], public access to information via the internet [10], and many other studies which employ a nuanced perspective of technology in order to understand the social shaping and consequences of ICT. Social informatics research also investigates new social phenomenon that materialize when people use technology, for example, the unintended effects of behavioral control in virtual teams [11]. Social informatics is not described as a theory, but as a "large and growing federation of scholars focused on common problems", with no single theory or theoretical notion being pursued [4]. What social informatics does provide is a framework for conducting research. The framework of social informatics research is that it is problem orientated, empirical, and interdisciplinary with a focus on informatics.

Social informatics research in the area of LBS and OSN has highlighted the implications of using these technologies, including the concepts of trust, control, privacy and security. In addition OSN studies have exposed the ability of these technologies to alter and impact upon social relations. These studies provide a guide for concepts of interest to study in terms of the emergent technology of LBSN. Studies on LBSN however have not investigated the implications of the use of sophisticated LBSN applications, as are currently available. This research aims to address this gap by engaging in a social informatics based investigation of the implications of LBSN.

The problem addressed by this research is: under what conditions do location based social networking technologies enhance or reduce trust between "friends"? This research is concerned with the formulation of the socio-technical landscape that location based social networking applications exist within. The purpose of which is to understand the bidirectional relationship of society and technology and discover the circumstances within which trust will be negatively affected by the use of the technology. The nature of social informatics warns against a simplistic cause and effect approach to technology [12]. As such this research topic does not contain simple propositions that A causes B, rather it is developed upon a set of questions that reflect the interrelated social and technical aspects of the research.

- Who are the users of the technology?

- What is the technology used/misused for?

- What relationships will it be utilized within?

- How is trust categorized in these relationships?

- What circumstance(s)/ context will it be used for?

- What are the technological capabilities?

\section{FOCUS GROUPS}

A focus group is a "research technique that collects data through group interaction on a topic determined by the researcher" [13]. A key characteristic of focus groups is the insight and data produced by the interaction of the participants [14]. Focus groups are primarily used within preliminary or exploratory stages of a study [15]. This study uses focus groups to explore and discuss the use and implications of LBSN with the aim of generating a nuanced understanding of the socio-technical framework that LBSN operate within. The unit of analysis for the study was both at the individual and group level [16]. Focus groups enable individuals to express their "attitudes, beliefs and feelings" and the interaction between participants enables these views to be explored on a group level.

\section{A. Design}

Five focus groups were conducted for this study. This is justified on the basis that data becomes "saturated" with very little new content emerging after the first few sessions are conducted. The focus groups were conducted with students enrolled in a third year core subject covering professional practice and ethics, in the information technology and computer science curriculum at the University of Wollongong in the first week of May 2009. The background of these students means that it can be assumed that they are technology literate and able to grasp and understand (if not already using) emerging technologies. The focus groups were run in the tenth week of session, when it could be assumed that students were equipped with refined analytical skills to identify ethical and social aspects of technology. A further benefit in utilizing tutorial classes for the study is that the groups were pre-existing and therefore group members were able to easily relate, and also comment upon incidents which they shared in their daily lives [17].

Large focus groups can consist of between 15 to 20 participants and are appropriate for topics that are not emotionally charged. Larger groups are renowned for containing "a wide range of potential responses on topics where each participant has a low level of involvement" [13]. It should be noted that each focus group in this study had on average 15 active participants. The majority of participants were aged between 18 to 22 years old with several mature age students aged between 30 to 45 years old in each class. There was an approximate 60/40 mix of domestic and international students in each of the focus groups. The majority of international students came from China and Singapore.

\section{B. Questions and Stimulus Material}

Two moderators were used to conduct the focus groups. In order to maintain consistency between moderators and encourage a neutral approach to the focus group discussion a Question and Stimulus pack was created. The moderators played an active but neutral role, facilitating discussion and probing the participants in order to engage a deeper discussion of the issues. The purpose of developing the focus group questions and stimulus material was threefold; firstly to ensure conformity and standardization across all focus groups, secondly to provide direction and stimulus for the discussion and thirdly to provide participants with knowledge relevant to the focus group discussion. Furthermore the questions and stimulus material enabled the focus group to be structured into three sections of enquiry as demonstrated in figure 2 .

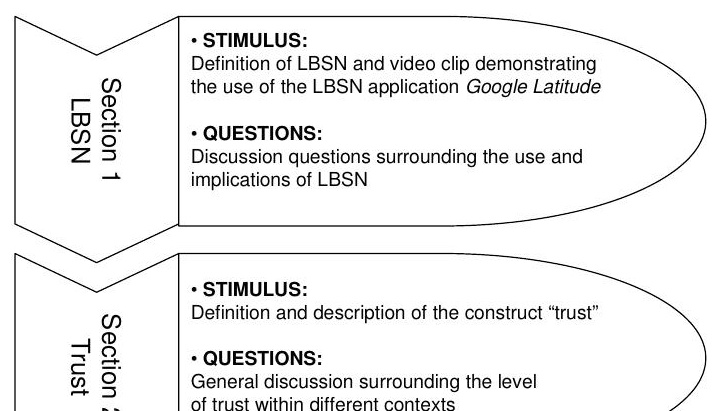


Figure 2. Focus Group Sections

The purpose of the focus group questions was to obtain an understanding of the socio-technical framework of LBSN. In order to develop the questions the researcher reviewed the literature on LBS, LBSN, OSN and Trust, along with general media, including blogs and web articles on LBSN and Google Latitude. The questions developed focused upon:

- Whether participants would use LBSN

- Why would/(not) participants use LBSN

- Who they would allow to see their location

- Who they would like to know the location of

- What issues surround the use of LBSN

- The use of LBSN in relationships generally

- The use of LBSN in relationships focusing on trust In order to facilitate discussion, open-ended questions were used.

\section{Data Analysis}

The first stage of the data analysis is the transcription of the focus groups. The data was then analyzed by drawing "together and comparing discussions of similar themes... [to] examine how these relate[d] to the variables within the sample population" [17]. The method of analysis was manual qualitative content analysis. Qualitative methods are constructivist in approach [18]. They take an "interpretive, naturalistic approach to [their] subject matter" and explore things in "their natural setting attempting to make sense of, or interpret phenomena in terms of meaning people bring to them" [19]. In most cases, qualitative research results in the discovery of themes and relationships. Qualitative content analysis is concerned with capturing the richness and describing the unique complexities of data and as such provides understanding. This method allows the researcher to position, relate and ultimately understand the abstractly inferred content from a higher level processing of text and interaction.

\section{RESULTS}

\section{A. Propensity to Adopt LBSN}

There were three categories of response to the question would you use LBSN: adoption, non-adoption and those who had already adopted. Within each of these categories there was a spectrum of responses with participants identifying conditions of adoption or non-adoption to qualify their position. Overall most participants were in favor of nonadoption. Each of these categories of response is explored below.

\section{1) Participants who had Adopted LBSN}

Two participants had already adopted a LBSN application. In both cases the LBSN chosen was Google Latitude. One of the participants had ceased using Latitude while the other still had it installed. The participant who no longer used Latitude stated: "I got it and got rid of it because it was just weird". When the participant was asked why it was "weird" they responded: "because it was like running in the background and you could either sign in and then it kept logging in all the time and I didn't want my brother knowing where I was all the time." The only person who this respondent had listed as a "friend" on Latitude was his brother as at the time, Latitude was fairly new and the respondent did not think that many people used it.

The second participant who had adopted LBSN, and was still using it was doing so without any "friends". This participant noted that Latitude: "really wears the battery down fast. I'll exit Google Latitude and it will ask- 'would you like to continue sharing your location' and I'll do that but then I'll have no battery left. So it is kind of useless. I still have it. Every now and then I'll log in and update my location. There is not a lot of point." This second participant observed that without updating your location automatically there is "not a lot of point" to the application. The barrier to allowing automatic updates in the second participant's view was not the "weird" feelings it generated, but the battery power requirement. However this user had "no friends" registered to share their location with.

\section{2) Participants who would Adopt LBSN in the Future}

Of the participants who responded that they would adopt a LBSN like Google Latitude, most set out conditions of use to qualify their position while others identified availability of technology to support Latitude as a barrier to adoption. Some focus group participants were indifferent while others identified that they were open to adopting the technology without imposing any specific conditions. The conditions of use that participants specified were the accuracy of the device/application, the level of control over the visibility of their location and when the application would be used.

The condition of adoption based upon the accuracy of the device was expressed in terms of both high and low accuracy. In terms of low accuracy one participant expressed: "Participant: Depends how accurate. IModerator: Accurate down to street level. IParticipant: I think that would be kind of weird, I wouldn't like that." This participant perceived street level accuracy as "weird", and stated they would not adopt LBSN if it had such a high degree of accuracy. In terms of high precision accuracy one participant said that they would use a LBSN but "it would have to have a high quality network." This participant had used LBSN before in China but experienced problems with it and after a 
"one day test ... I didn't go ahead because the feasibility and reliability was not good, it had nothing to do with the privacy problems."

Several participants would use LBSN upon the condition that they would be able to control the visibility of their location. Visibility was expressed in terms of controlling the level of location information (no information or street, suburb and state level) displayed, as well as control over who had access to the location information. In terms of visibility one participant commented that they would use it if they could specify: "[d]ifferent levels of visibility. Gaming friends at the state level; family - no problem because you trust them; girlfriend - no problem. Obviously the level of relationship trust would be the determining factor in how much access each person would be able to have." This participant identified that the level of location information disclosed correlated to the different level of trust in each relationship. Other participants simply desired the ability to "easily block your location at all times" or "deactivate" the device.

In relation to who has access to location information one participant indicated that they would use it: "only on family. ... Or if children are alone [and] I want to know where they are. But not with friends because if friends know where I am maybe they wonder why I am there and they ask and I have to answer like small, small details..." Identifying that some people do not want to disclose information about themselves to friends as it would open up a Pandora's box of questions about where they were and what they were doing and who they were with and so on. Another participant stated they would use LBSN but "confine it to a restricted group like ... close family", while another would use it if they had kids: "[i]f I have kids I will put it on their phone".

Participants identified that they would only use LBSN in certain situations for example one participant said they would only use it if they were traveling stating: " $[\mathrm{t}]$ he only use I see in it is if I was traveling. I went on a holiday in Tasmania and my mum was worried about where I was because I wouldn't contact her and stuff. And with this she would be able to know where I am constantly, and if I am lost somewhere they would know the last place I was at." Another participant identified that: "[t]his thing comes in really handy in unforeseen situations, maybe you are in a car and you cannot call a person to come along. So those are a few situations where it can be helpful but for security and privacy. If I can find myself in the database and I can only be seen by my close family that will be really good." This demonstrated that there were situations within which the utility of LBSN would motivate individuals to adopt the technology although there were some concerns about security and privacy by some participants.

Finally there were three responses which did not identify conditions upon adoption. The first response was by a participant who would adopt LBSN however, they did not have the requisite device. They reflected: "the technology that I have will not let me [conduct LBSN] because I have an older phone. I tried using it but it wouldn't work." The second response identified that they would use it without conditions and that it did not pose any privacy concerns for them. I'd "use it but I'd stop using from boredom more than anything else, it wouldn't be because of privacy. There doesn't seem like there is a point to it. It is not a privacy thing." The final response to mention in this section is by a participant who was open to the adoption of LBSN. "I reserve judgment until I see it in action. The general idea is pretty useful I guess. I am open to it. If you have someone's email address you can find out where they live and you can find out anything you want about them... I'm not too worried about it at this point because I think it is probably too late to start worrying about how much protection ... you know... your identity and your location, it's all out there." This participant drew upon the idea that identity and location information is already available on the Internet or in caller detail records or direct marketing material, concluding that it is therefore "probably too late to start worrying about how much protection" we place on further exposure of location information.

\section{3) Participants who would Never Adopt LBSN}

The majority of participants indicated that they would not adopt LBSN. Participants gave the following reasons; it is unnecessary or a hassle, it raises ethical concerns, segregates from human contact, or they did not want to disclose their location. The participants who identified that it was unnecessary or a hassle included the following responses: "I don't have time" | "Would be a hassle I don't use stuff like that" I "Unnecessary, I don't care exactly where my friends are. I wouldn't use it to find them whether or not they would use it to find me" I "If you are a close enough friend then would you not just call them?" | "There are other ways of getting in contact, so do we need this location based networking to get in contact. Phone calls are easy enough to make. I am saying you can have it, it is just social networking, whatever, if you just want to keep in contact with friends and that but you can also do that in other ways as well." All these responses indicate the view of some participants that LBSN is not a necessity, and that existing technologies can be used or should be used- "would you not just call them?" A side note to observe from the latter three responses above is that these participants regarded the existing technologies, which do not allow for unobtrusive observation of location, should be used in preference to LBSN.

Participants identified a range of ethical concerns from using LBSN to prank people "because they trust it", such as LBSN being used by "serial killers" or for the purpose of "stalking". More detailed ethical concerns were discussed in responses to "Why would/(not) participants use LBSN?" In addition to the ethical concerns one participant commented that LBSN would change the dynamics of communication with the effect of segregating users from human contact. "It segregates people from human contact. Instead of calling them up and asking them what they are doing, you will just search thlem and see what they are doing without them knowing. It is like stalking."

A large proportion of the participants who would not use LBSN explained their view on the basis that they did not want to share their location information. Some of the 
remarks included that LBSN was "[a]nother layer of what people already know about you" I "I don't like people knowing where I am half the time" I "I wouldn't use it. I just don't want everyone knowing where I am 24/7. Even if like you have the option to turn it off or whatever, I would still feel like even when it is off it is kind of... I don't know I'd still feel unsure about it" I "like you may forget to turn it off and not want people to know where you are like, if you are cheating on your girlfriend. And if she goes on and sees that you are at another girl's place" I "If you have it on 24/7 and then there are brief stints where it is off then people are like "he is up to something" or "what is he doing now". Even if they don't know what you are doing, they might think that you are doing something suspect because this is the time that it is off" I "People like to do that - they like to think 'Oh he could be doing something suspect, lets find out what it is'."

Two key ideas emerge from these responses. Firstly, that some people are concerned about revealing too much information about themselves like "I don't want everyone knowing where I am 24/7". Secondly that revealing location can be dangerous- not in and of itself- but because of what people do with that information. As the latter two responses illustrated, people's curiosity and desire for gossip can lead them to use location information for the wrong purposes and infer "suspect" scenarios.

\section{B. Reasons Why Participants Would/Would Not Use LBSN}

The second discussion question was why or why not participants would use LBSN. Some participants provided reasons for their position in response to the first question, however this second question required the respondents to expand upon that discussion and identify specific purposes for using and not using LBSN regardless of their response to the first question. The participants' responses are summarized in Table I with a discussion of the responses in the two following sections.

\begin{tabular}{|c|c|}
\hline Reasons to use LBSN & Reasons not to use LBSN \\
\hline 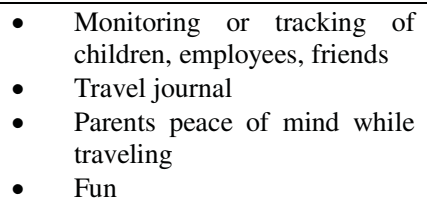 & $\begin{array}{ll}- & \text { Intrusion into peoples' lives } \\
\text { - } & \text { Impact upon trust } \\
\text { - } & \text { Drain the batteries in device } \\
\text { - } & \text { Privacy } \\
\text { - } & \text { No one uses it }\end{array}$ \\
\hline
\end{tabular}

\section{TABLE I. REASONS TO USE/NOT USE LBSN}

\section{1) Reasons Why Participants Would Use LBSN}

The reasons that participants stated they would use LBSN included the ability to keep track of or monitor children, employees or friends, store a travel journal for themselves and others to view, to provide parents or carers with peace of mind while they were traveling or for fun. Following are excerpts of some of the responses provided by the participants.

In relation to monitoring or tracking participants expressed: "[t]he only reason that I would use it is if I wanted to know where someone was and they weren't telling me where they were" | "Well if you were one of those people who always had to know where someone was then it would be useful because then you wouldn't be always calling them [saying] "where are you, where are you?", "If I had a business I would use it on my employees, especially if they had their own vehicles, so I would know where the employees are going."

Participants also expressed that they would use LBSN if they were traveling: "[t]he only use I see in it is if I was traveling"| "Used for traveling, when you want your friends back at home to keep track of where you are" I "If you are traveling from location to location so you can see where you are and also for people who want to see where you are and who want to know what time to expect you. So they can see how long it will take before you arrive."

And finally one participant noted that "maybe I would use this just for fun. Like, 'where are you?' for fun. If I don't want to use it, I'll just turn it off'.

\section{2) Reasons Why Participants Would Not Use LBSN}

Participants gave several reasons why not to use LBSN including that it would present an intrusion into peoples' lives, impact upon trust, drain the batteries in the device, present privacy concerns and because no one else uses it. Following are some excerpts to clarify and expand upon these reasons.

Participants who identified that LBSN presents an intrusion into peoples' lives made the following comments: "[c]omes across more as a tool for surveillance rather than a social networking tool" | "Parents putting it on their children's phone - negative use for it. Good for the parents but I don't think the child will like it" | "It is just an intrusion into your kid's life, that really shouldn't be there - too much of an intrusion and not enough freedom for when you are getting older and everything, and deserve more freedom" । "Coming home from work and going to the bar but saying to your wife that you are stuck in traffic- 'oh really but it says you're at the bar, honey'... That kind of problem would come up because people have a tendency to be doing things that they are not supposed to be doing." These comments illustrate how LBSN can stand in the way of the human desire for freedom and autonomy with the ability to stray from plans.

Participants merely stated that privacy, trust and battery life were reasons for non-use. The participants however elaborated more upon the reason that no one else uses LBSN stating that: "I probably would not use it because no one else uses it so why would I have it. Like it might not be popular now so that is a reason for now, but in the future when everyone else has it, it might not be a reason. So its popularity might affect whether or not I would use it." In response to this remark another participant commented that: "But when things become more popular, like MS Windows, then people decide to hack MS Windows because it is the same thing that everyone uses. So if everyone started using this, someone out there might find a way to hack it and take advantage of it."

\section{Viewing and Disclosing Location}

Participants were asked "Who would you allow to see your location?" and "Who do you want to view the location 
of?" More responses were elicited from the first question, demonstrating that participants are more concerned with who is able to see their location rather then who they can see. Table II below summarizes the participants' responses.

\begin{tabular}{|c|c|}
\hline People who can View & People to View \\
\hline $\begin{array}{ll} & \text { No one } \\
\text { - } & \text { Family/ close friends/ trusted } \\
& \text { people } \\
\text { - } & \text { Friends } \\
\text { - } & \text { Anyone } \\
- & \text { Everyone }\end{array}$ & $\begin{array}{ll}- & \text { Everyone } \\
\text { - } & \text { Friends } \\
\text { - } & \text { Prime Minister Kevin Rudd } \\
\text { - } & \begin{array}{l}\text { Parents (depending on the } \\
\text { circumstances) }\end{array}\end{array}$ \\
\hline
\end{tabular}

TABLE II. VIEWING AND DISCLOSING LOCATION INFORMATION

The majority of participants would allow their "family" or "close friends" to view their location or specified people that they considered to be "really really trusted". Many participants would allow "family" or "close friends" but not both categories. One participant specified that they "would not request [to use LBSN with] any family member [but]... I might accept it if they add me but I would never actually ask this from my family". Another participant would add a sibling but not parents and when asked why not stated that: "I tell them a lot but I just don't want them to know absolutely everything. There is this thing where you want to be your own person, have your own space, you don't want to be like trapped. Because you act differently because you think 'oh shit my parents are always going to be watching what I am doing and where I am' and that is not good, I don't like that."

Some participants would add their friends, however specified that it would not be just an acquaintance or "some mate you just bumped into on the road". However other participants would add everyone or anyone: "Everyone who would really want to know where I am? ... unless I win the lotto"| "I'd let anyone. But I would turn it off if I was doing something that I didn't want people to know about" । "If you were doing something and you wanted privacy you would turn it off. But otherwise if people want to enjoy laughing at where I am then I don't really mind." Although these participants did identify that they would allow anyone or everyone, they did impose some conditions upon their answer. The participants were not as specific about who they would view the location of. Many suggested that they would want to track everyone, even Prime Minister Kevin Rudd, or just their friends.

\section{ISSUES SURROUNDING THE USE OF LBSN}

The focus group participants were asked what they thought were the potential issues with the use of LBSN. Figure 3 represents the broad categories of responses provided by the participants. The shade of color provides an indication of the number of times each issue came up within the focus groups; the darker the shade, the greater the frequency the issue arose. Security was the premier concern, followed by privacy and trust. Social relations, control, and technological issues were also important to participants.

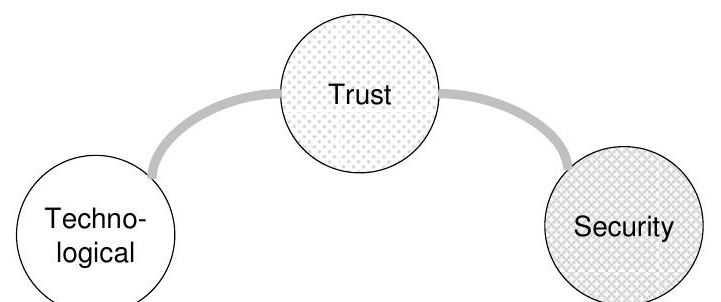

Figure 3. Issues Surrounding LBSN

\section{A. Security}

The focus groups drew out three main issues in relation to security; security of self, security of information and security of others. In relation to security of self, participants commented that LBSN could be: "used as a bullying thing... if you see someone in an area and there is no one else really around that area then bullies could go and use it to get that person". Another participant identified that "I can watch you on Google Latitude - if you update it every three or four hours and know where you are and build a profile". Other participants mentioned that it could be used for "stalking" or "pedophile tracking." One participant commented that it could be used for covert tracking: "I think that if the location is set to continuous tracking there won't be any notification sent from Google Latitude. So if anyone gets a hold of your mobile and sets it to continuous tracking they can follow you around." The scenario depicted by this participant however, is not entirely accurate, as Latitude does provide notification that it is running in the background, however this notification is only given once a month for the first few months and then once every three months. Therefore covert tracking with latitude would be possible for at least one month or in other cases a few weeks. There are some other LBSN applications that are now entering the market, however, that provide no notification whatsoever.

Participants questioned the security of information retained by the service provider, questioning whether Google would "share our information", or third party hackers who would "hack into the system [and then] would be able to find whoever, whenever". In relation to security of others one participant noted that "[my friend's] location and activities are secured to me, as long as I have my cell phone. If I lose it, and another person finds it ... they can easily see the location of my friends". Therefore having the ability to access a friend's location information can pose a potential threat to the other person's security if the device is lost, stolen, or given to a third person not authorized to view the location information. 


\section{B. Privacy}

Participants identified privacy as an issue, as LBSN applications primarily involved sharing personal information. The main issue, which emerged, was the intrusion into personal life caused by LBSN. Example remarks included: "[s]omeone can track you and see whether you have gone to a medical centre, so if you wanted to be tested on something and you didn't want anyone to know about it because you would be rejected by society" | "random things like being at the doctor's surgery and having the phone in your pocket and you don't want everyone prying into your life" | "if you were doing anything - not necessarily a crime - but something you wanted to keep secret." An additional issue was questioning the privacy policy of Google Latitude (and therefore Google) and whether that would "override" the legislation of some jurisdictions to allow for law enforcement authorities who have a warrant to obtain detailed records of one's location.

\section{Trust}

Participants identified three ways that LBSN could affect trust. Firstly, LBSN users could use the application to "lie" or "hide things", taking advantage of the trust other users place in the device and creating situations of false trust. Secondly, that LBSN could cause people to "start losing trust - losing trust between everyone, between your closest friends, your boyfriends, girlfriends", and would make people "start questioning everything and everyone and get bitter and old and grey and home alone". Therefore LBSN would discourage trust and create distrust between individuals. Finally, participants identified that LBSN would provide people with the ability to look "too deep, watching who is where and who is near, and infer little schemes or soap operas", and contribute to "random social problems when someone looks up their boyfriend and there is some other person at their house". Both the latter two comments, present scenarios where the user places greater trust in the device than the individual being monitored, and this shift in trust is the cause of the social problem.

\section{Control}

Participants commented that "lovers" or "parents" could use LBSN as a method of exerting control. In both proposed scenarios, the control was seen as a pre-existing element of the relationship, and LBSN as a tool for exercising control. Some control-related comments which were representative in the use of LBSN included: "control by a crazy lover" | "it is not about the children it is about having access to the children. About control." One participant, as noted earlier, spoke about control with respect to owning one's space, and therefore owning one's personhood. This participant noted parental control in this context was a form of indirect control. They might not be telling you what to do, but they are keeping tabs on you.

\section{E. Social Relations}

Participants also commented on the effect of LBSN upon social relations. "It takes away from the social part of social networking; we are not communicating with each other we are... just viewing it and it is more of a pervasive thing or voyeuristic thing than a social thing"| "People might use it to avoid certain people as well." It was noted by another participant however, that at the same time, LBSN could also be used to generate discussion.

\section{F. Technological}

Technological issues identified were related to perceived battery consumption, and whether the location tracking/ monitoring technology would work indoors. Reliability and accuracy were also important factors discussed, as was whether all new mobile devices now had the feature built in and whether data charges applied to usage.

\section{G. No Issues}

Some participants commented that there were no issues with LBSN: "[t]he Google Latitude application is great, if you don't like the system you can deactivate it," and "[n]o issues, if your friends location is secured to you, so long as you have the phone."

\section{DISCUSSION}

People and relationships form the backbone of society. Pahl [20] describes friendship as a "social glue" that provides the fulfillment of the "need for belonging and 'reliable alliance' - that is, for a bond that can be trusted to be there for you when you need it" [3]. Research on social networking applications, shows that new technologies can have potential negative implications upon social relationships [21] and privacy [22]. Additionally, location based services (LBS) have social ethical implications [23]. Social networking applications have the potential to become an engrained and integral part of social interactions causing those who do not have the technology to be either excluded or succumb to the adoption of the technology [22]. A bad experience with a LBSN may not only impact an individual, but one's relationships, and more broadly one's ability to trust in others and in society more generally. One might ponder that having knowledge of where someone is all the time should in fact enhance trust, that there is certain predictability behind where a loved one physically is located or where they say they are located. However, technology is not perfect, it is not always accurate, it does not always work as it should, and there is no such thing as a perfect "location" system. Humans also require their autonomy, their freedom, an ability to make every-day mistakes without prying eyes [24].

\section{A. Theoretical Importance}

This research provided an investigation of the sociotechnical context of location based social networking technologies and applications in terms of "trust" and "friendship". Such an investigation has several theoretical contributions. Firstly, it provides an understanding of the concepts of trust, friends and friendship within the context of information communication technologies, and social networking in particular. Secondly, it adds to the scholarship in the area of social informatics, providing an example of how social informatics as a theoretical framework can be 
employed to arrive at a holistic contextualized understanding of the operation of ICTs. Thirdly, it contributes to the limited scholarship on location based social networking with the view to continue the scholarly dialogue on the design, use and implementation as well as implications of the technology and ICTs in general.

\section{B. Practical Importance}

Trust and friendship are important aspects of society, and as such the implications of the use of technology upon these concepts are important from a practical as well as a theoretical perspective. The outcomes of this research can be utilized to inform the creation of policy, guidelines or legislation designed to curb the negative implications of the technology upon society. A recent paper by Grimmelmann [25] argued that although "policy makers cannot make Facebook completely safe... they can help people use it safely", similarly this applies to the emergent technology of LBSN. The outcomes can also be used to educate individuals, and provide stimulus for a dialogue within the broader community about the implications and benefits of social networking and location-based services. Additionally, the designers of the technology can utilize this research by incorporating concerns or user requirements in new or existing applications.

\section{CONCLUSION}

LBSN applications provide users with the ability to conduct real time social surveillance upon their friends, including the acts of real-time tracking and monitoring. This study, through the conduct of a social informatics investigation into LBSN, has identified the potential implications of use of LBSN upon relationships, including its critical effect upon trust. The potential implications can be summarized as security, privacy, trust, control, and an impact on societal relationships. The results from the focus group provided a broad view of the use, design, implementation and context of LBSN, and insight into the possible implications of use. The conclusion to be drawn from this study is the nuanced understanding of the operation of LBSN and its implications as well as the circumstances within which it will have a negative impact upon trust. In addition, this research identified that LBSN did present a credible threat to trust between "friends" and that LBSN applications need to be more robustly designed and implemented to reduce the evident potential for an individual user to suffer harm at the hands of another.

\section{REFERENCES}

[1] R. Kling, "What is social informatics and why does it matter?" The Information Society, vol. 23, no. 4, 2007, pp. 205-220.
[2] K. Robert and K. Sara, "Internet paradox revisited," Journal of Social Issues, vol. 58, no. 1, 2002, pp. 49-74.

[3] B. Misztal, Trust in Modern Societies- The Search for the Bases of Social Order, Cambridge: Blackwell, 1998.

[4] S. Sawyer and K. Eschenfelder, "Social informatics: perspectives, examples, and trends," Annual Review of Information Science and Technology, vol. 36, no. 1, 2002, pp. 427-465.

[5] R. Kling, "Learning about information technologies and social change: the contribution of social informatics," The Information Society, vol. 16, no. 3, 2000, pp. 217-232.

[6] R. Kling, "Social informatics," Encyclopaedia of Library and Information Science, 2003, pp. 2656-2661.

[7] R. Kling, "Social informatics: a new perspective on social research about information and communication technologies," Prometheus, vol. 18 , no. 3, 2000, pp. 245-264.

[8] R. Kling and L. Covi, "Electronic journals and legitimate media in the systems of scholarly communication," The Information Society, vol. 11, no. 4, 1995, pp. 261-71.

[9] W. Orlikowski, "Learning from notes: organizational issues in GroupWare implementation," The Information Society, vol. 9, no. 3: 1993, pp. 237-50.

[10] B. Kahin and J. Keller, Public Access to the Internet. Cambridge, MA: MIT Press, 1995.

[11] G. Piccoli and B. Ives, "Trust and the unintended effects of behvaior control in virtual teams," MIS Quarterly, vol. 27, no. 3, 2003, pp. 365-395.

[12] D. Mackenzie, "Introductory essay," The Social Shaping of Technology, Philadelphia: Open University Press, 1999, pp. 2-27.

[13] D. Morgan, Focus Groups as Qualitative Research, California: Sage Publications, 1996.

[14] A. Gibbs, "Focus group research," Social Research Update, vol. 19, 1997, pp. 1-4.

[15] R. Krueger and M. Casey, Focus Groups: A Practical Guide for Applied Research, California: Sage Publications, 2000.

[16] P.S. Kidd and M. B. Parshall, "Getting the focus and the group: enhancing analytical rigor in focus group research," Qualitative Health Research, vol. 10, no. (3), 2000, pp. 293-308.

[17] J. Kitzinger, 1995, "Qualitative research: introducing focus groups," British Medical Journal, vol. 311, no. 7000, 1995, pp. 299-302.

[18] D. Druckman, Doing Research: Methods of Inquiry for Conflict Analysis, California: Sage Publications, 2005.

[19] M.D. Gall, W.R. Borg, J.P. Gall, Educational Research: An Introduction, New York, 1996.

[20] R.E. Pahl, On Friendship, Wiley-Blackwell, 2000.

[21] R. Gross and A. Acquisti. "Information revelation and privacy in online social networks," Workshop on Privacy in Electronic Society, Virginia, USA, ACM, 2005.

[22] D. Boyd and N. Ellison, "Social network sites: definition, history, and scholarship." Journal of Computer-Mediated Communication, vol. 13, no. 1, 2008, pp. 210-230.

[23] M.G. Michael, S.J. Fusco, K. Michael, "A research note on ethics in the emerging age of überveillance," Computer Communications, vol. 31, no. 6, 2008, pp. 1192-1199.

[24] M.G. Michael and K. Michael, "Uberveillance: microchipping people and the assault on privacy," Quadrant, vol. 53, no. 3, 2009, pp. 85-89.

[25] J. Grimmelmann, "Saving Facebook: privacy on social network sites," Iowa Law Review, vol. 94, no. 4, 2009, pp. 1137-1170. 